\title{
FAHP and TOPSIS Prediction of Diamond Segments Wear When Using Frame Saw to Cut Granites
}

\author{
Qin Sun, ${ }^{1,2,3,4}$ Jinsheng Zhang, ${ }^{1,2,3}$ and Jibo $\mathrm{Hu}^{1,2,3}$ \\ ${ }^{1}$ School of Mechanical Engineering, Shandong University, Jinan 250061, China \\ ${ }^{2}$ Research Centre for Stone Engineering, Shandong Province, China \\ ${ }^{3}$ Key Laboratory of High-Efficiency and Clean Mechanical Manufacture (Shandong University), Ministry of Education, Jinan, China \\ ${ }^{4}$ School of Mechanical Manufacturing and Automation Engineering, Shandong Yingcai University, Jinan 250104, China
}

Correspondence should be addressed to Qin Sun; sunhaiqin1998@163.com and Jinsheng Zhang; zhangjs@sdu.edu.cn

Received 17 August 2017; Accepted 19 October 2017; Published 12 November 2017

Academic Editor: Nazrul Islam

Copyright (c) 2017 Qin Sun et al. This is an open access article distributed under the Creative Commons Attribution License, which permits unrestricted use, distribution, and reproduction in any medium, provided the original work is properly cited.

Fuzzy Analytic Hierarchy Process (FAHP) and Technique for Order Preference by Similarity to Ideal Solution (TOPSIS) approaches were employed to predict the sawability of a diamond frame saw to cut granites. FAHP is used to determine the weights of the criteria of decision-makers and TOPSIS is used to rank sawability. The sawability was evaluated by diamond segment wear. The prediction of segment wear is important to determine the segments service life and sawing cost and may determine cutting parameter selection for a given stone. Sawing experiments were conducted to verify the analysis result of the applied method in this study. The experimental results are in good agreement with the theoretical analysis. The ranking method can be used to evaluate segment wear. Stone properties, such as uniaxial compressive strength, shore hardness, quartz content, and bending strength, must be determined for the best segment wear ranking.

\section{Introduction}

The prediction of stone sawability directly affects cutting parameter selection and sawing cost estimation for stone companies. A reasonable prediction of stone sawing can make the process more efficient. Scholars have studied the prediction of sawability by using diamond tools to cut stones. Stone sawability is related to rock properties and cutting parameters. Sawability criteria are mainly based on power consumption, slab production rate, specific cutting energy, classification, segment wear, and sawing efficiency. The main evaluation methods mainly include fuzzy analytic hierarchy process (FAHP) and Technique for Order Preference by Similarity to Ideal Solution (TOPSIS) approaches, artificial neural networks, multiple regression statistical analysis, and multifactorial fuzzy approach. Brazilian tensile strength, uniaxial compressive strength, hardness, bending strength, quartz content, Young's modulus, impact strength, shear strength, density, porosity, abrasivity, and grain size are the input parameters of the prediction model. The sawability criteria, main evaluation methods, and input parameters are presented in Tables 1, 2, and 3, respectively.

The effects of carbonate rock properties, such as uniaxial compressive strength, Schmiazek $F$-abrasivity factor, Mohs hardness, and Young's modulus on power consumption and production rate have been reported $[1,2]$. The artificial neural network method is better than the statistical regression method to product the slab production of carbonated stones by shear strength [3]. The influence of P-wave velocity, impact strength, point load strength, and Schmidt hammer value on slab production were evaluated [4]. A slab production prediction model was established using some rock properties, such as uniaxial compressive strength, Schmidt hammer valve, Los Angeles abrasion (LA abrasion), and Brazilian tensile strength [5]. The relationship between slab production and rock properties including uniaxial compressive strength, Brazilian tensile strength, Cerchar abrasivity index, porosity, and density was proposed [6]. A classification method of stone sawability was proposed, and the sawing rate was classified into five categories [7]. The influence of cutting 
TABLE 1: The main sawability criteria.

\begin{tabular}{|c|c|}
\hline Sawability criteria & References (researchers) \\
\hline Power consumption & Mikaeil et al. (2011) [1] \\
\hline Slab production & $\begin{array}{l}\text { Mikaeil et al. (2013) [2]; Kahraman et al. (2006) [3]; Kahraman et al. (2004) [4]; } \\
\text { Ataei et al. (2012) [5]; Tumac (2016) [6]; Mikaeil et al. (2011) [7]; Ersoy and Atıc1 } \\
\text { (2004) [8]; Fener et al. (2007) [9]; Sadegheslam et al. (2013) }\end{array}$ \\
\hline Specific cutting energy & Yurdakul and Akdaş (2012) [10] \\
\hline Classification & Tutmez et al. (2007) [11]; Delgado et al. (2005) [12] \\
\hline Segment wear & $\begin{array}{l}\text { Xu and Zhang (2004) [13]; Wei et al. (2003) [14]; Eyuboglu et al. (2003) [15]; Ersoy et } \\
\text { al. (2005) [16]; Özçelik (2007) [17]; Buyuksagis (2007) [18] }\end{array}$ \\
\hline Sawing efficiency & Buyuksagis and Goktan (2005) [19] \\
\hline
\end{tabular}

TABLE 2: The main evaluation methods.

\begin{tabular}{lc}
\hline Evaluation methods & References \\
\hline FAHP and TOPSIS & {$[1,2,20]$} \\
Artificial neural networks & {$[3,6,13]$} \\
Multiple regression statistical analysis & {$[4,5,7-10,15-19]$} \\
Multifactorial fuzzy approach & {$[11,13]$} \\
\hline
\end{tabular}

TABLE 3: The input parameters of the prediction model.

\begin{tabular}{lc}
\hline Input parameters & References \\
\hline Uniaxial compressive strength & {$[1,2,4,6-11,14-19]$} \\
Brazilian tensile strength & {$[4,7-11,15-19]$} \\
Hardness & {$[1,2,4,6-12,14-19]$} \\
Bending strength & {$[10,16]$} \\
Quartz content & {$[3,8,12,14,16-19]$} \\
Young' modulus & {$[1,2,8,15,16]$} \\
Impact strength & {$[4,8,9,11,16]$} \\
Shear strength & {$[3,8,16]$} \\
Density & {$[6,8,10,16,18]$} \\
Porosity & {$[6]$} \\
Abrasivity & {$[8,16]$} \\
Grain size & $2,4,6-9,11,14,16,18,19]$ \\
\hline
\end{tabular}

parameters and rock properties on specific sawing energy was reported [8]. Production can be predicted from LA abrasion loss, tensile strength, and compressive strength [9]. The specific cutting energy based on rock properties and cutting parameters was evaluated [10]. Sawing performance was classified into three categories, and the stone processing companies can select a suitable saw to cut stones only by the model developed [11]. Rock hardness has greatly influenced stone sawing rates compared with other stone properties [12]. The influences of cutting speed and depth of cut on segment wear were studied [13]. Segment wear and cutting force can be evaluated based on rock properties [14]. Shore scleroscope hardness, water absorption, and cone indenter hardness had a greater effect on segment wear than other rock properties [15]. The wear mechanism of diamond segments and a matrix was studied, and the cutting specific energy during the sawing process associated with segment wear was proposed [16].
The effects of mineralogical properties on segment wear and sawing speed were tested. Experimental results indicated that as the texture coefficient values increased, wear and sawing speed increased; however, as the grain size increased, segment wear decreased [17]. A predictive model of specific wear showed that plagioclase and bending strength were the most dominant rock parameters [18]. The optimum sawing performance for a particular stone based on depth of cut and travel speed was investigated [19].

Stone sawability when using a diamond frame saw to cut granite was predicted in this study. A prediction model was established by using segment wear as the evaluation criterion, and stone properties, including $\mathrm{SiO}_{2}$ content, quartz content, orthoclase content, plagioclase content, shore hardness, density, uniaxial compressive strength, and bending strength as input parameters, and FAHP and TOPSIS techniques were employed to evaluate the sawability.

\section{Theoretical Concepts}

\subsection{FAHP_Fuzzy Analytical Hierarchy Process}

2.1.1. Triangular Fuzzy Number. The theory of fuzzy sets was first proposed by Zadeh in 1965 [21]. The method of fuzzy comparison judgment based on triangular fuzzy number was described by van Laarhoven and Pedrycz in 1983 [22].

Definition 1. $M$ is defined as a fuzzy number on $U(U \in$ $(-\infty,+\infty))$, if its membership function $\mu_{M}(x): U \rightarrow[0,1]$, $\mu_{M}(x)$ is illustrated in

$$
\begin{aligned}
& \mu_{M}(x) \\
& = \begin{cases}\frac{1}{m-l} x-\frac{l}{m-l} & x \in[l, m] \\
\frac{1}{m-u} x-\frac{u}{m-u} & x \in[m, u] \\
0 & x \in(-\infty, l] \cup[u,+\infty) .\end{cases}
\end{aligned}
$$

Set $u$ and $l$ as the upper and lower bounds of the fuzzy number $M$, respectively, $m$ is the maximum value, and the triangular fuzzy number $(l, m, u)$ is shown in Figure 1 . 
TABLE 4: Relative weight of evaluation index.

\begin{tabular}{lc}
\hline Relative weight & Illustration \\
\hline$M_{1}$ & Criterion $i$ is equally important compared to criterion $j$ \\
$M_{3}$ & Criterion $i$ is moderately more important than criterion $j$ \\
$M_{5}$ & Criterion $i$ is more important than criterion $j$ \\
$M_{7}$ & Criterion $i$ is strongly more important than criterion $j$ \\
$M_{9}$ & Criterion $i$ is extremely more important than $j$ \\
$M_{2}, M_{4}, M_{6}, M_{8}$ & The scale value corresponding to the intermediate state \\
Reciprocal & If the ratio of $i$ and $j$ is $a_{i j}$, the importance of $j$ and $i$ is $a_{j i}, a_{j i}=1 / a_{i j}$ \\
\hline
\end{tabular}

Operation rules of two fuzzy numbers [23]: if $M_{1}=$ $\left(l_{1}, m_{1}, u_{1}\right)$ and $M_{2}=\left(l_{2}, m_{2}, u_{2}\right)$, the algorithms of $M_{1}$ and $M_{2}$ are as follows:

$$
\begin{aligned}
M_{1}+M_{2} & =\left(l_{1}+l_{2}, m_{1}+m_{2}, u_{1}+u_{2}\right), \\
M_{1} \times M_{2} & =\left(l_{1} l_{2}, m_{1} m_{2}, u_{1} u_{2}\right), \\
\lambda \times(l, m, u) & =(\lambda l, \lambda m, \lambda u) \quad \lambda>0, \lambda \in R, \\
\frac{1}{M} & \approx\left(\frac{1}{u}, \frac{1}{m}, \frac{1}{l}\right) .
\end{aligned}
$$

2.1.2. Fuzzy Analytic Hierarchy Process. The method of fuzzy analytic hierarchy process has been used widely $[24,25]$, and it is divided into several steps: constructing the fuzzy judgment matrix, determining the initial weight, and gaining the final weight, as described next.

(1) Constructing the Fuzzy Judgment Matrix. Figure 2 shows the relative weight of the evaluation index. Based on a ninepoint fundamental scale [26], the triangular fuzzy judgment set is provided in Table 4 [27]. According to this nine-point fundamental scale, experts compare each group (such as $C_{1}$ and $C_{2}$ ) to get a fuzzy number:

$$
\left(l_{1}, m_{1}, u_{1}\right),\left(l_{2}, m_{2}, u_{2}\right), \ldots,\left(l_{n}, m_{n}, u_{n}\right) .
$$

Then the fuzzy numbers are integrated:

$$
\begin{aligned}
& \left(\frac{l_{1}+l_{2}+\cdots+l_{n}}{3}, \frac{m_{1}+m_{2}+\cdots+m_{n}}{3},\right. \\
& \left.\frac{u_{1}+u_{2}+\cdots+u_{n}}{3}\right) .
\end{aligned}
$$

(2) Determining the Initial Weight. Let $X=\left\{x_{1}, x_{2}, \ldots, x_{n}\right\}$ be an object set and $U=\left\{u_{1}, u_{2}, \ldots, u_{n}\right\}$ be the target set, as described [28]. The degree analysis values for each object are recorded as $M_{g i}^{1}, M_{g i}^{2}, \ldots, M_{g i}^{m}, i=1,2, \ldots, n$, where $M_{g i}^{j}(j=$ $1,2, \ldots, m)$ are triangular fuzzy numbers.

The fuzzy synthetic value (initial weight) of the first $i$ object is expressed as follows:

$$
S_{i}=\sum_{j}^{m} M_{g i}^{j} \otimes\left[\sum_{i=1}^{n} \sum_{j=1}^{m} M_{g i}^{j}\right]^{-1},
$$

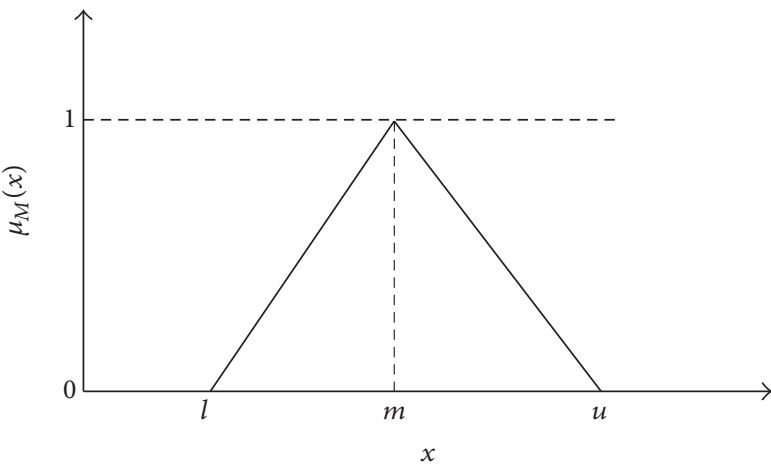

FIgURE 1: Triangular fuzzy number membership function.

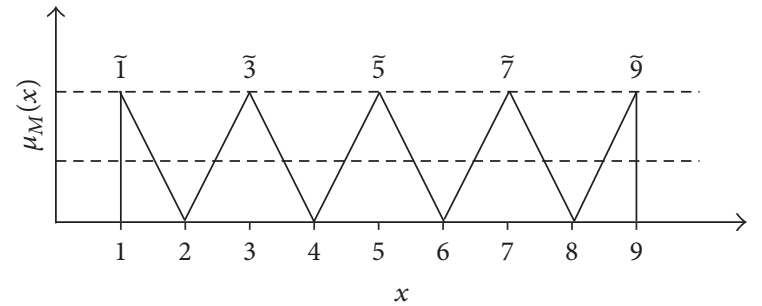

FIGURE 2: Fuzzy numbers of linguistic variable set.

where

$$
\begin{aligned}
\sum_{j=1}^{m} M_{g i}^{j} & =\left(\sum_{j=1}^{m} l_{j}, \sum_{j=1}^{m} m_{j}, \sum_{j=1}^{m} u_{j}\right), \\
\sum_{i=1}^{n} \sum_{j=1}^{m} M_{g i}^{j} & =\left(\sum_{i=1}^{n} l_{i}, \sum_{i=1}^{n} m_{i}, \sum_{i=1}^{n} u_{i}\right), \\
{\left[\sum_{i=1}^{n} \sum_{j=1}^{m} M_{g i}^{j}\right]^{-1} } & =\left(\frac{1}{\sum_{i=1}^{n} u_{i}}, \frac{1}{\sum_{i=1}^{n} m_{i}}, \frac{1}{\sum_{i=1}^{n} l_{i}}\right) .
\end{aligned}
$$

\section{(3) Gaining the Final Weight}

Definition 2. $M_{1}$ and $M_{2}$ are two triangular fuzzy numbers. If $M_{1}=\left(l_{1}, m_{1}, u_{1}\right)$ and $M_{2}=\left(l_{2}, m_{2}, u_{2}\right)$, the possibility degree of $M_{1} \geq M_{2}$ is defined as triangular fuzzy function:

$$
V\left(M_{1} \geq M_{2}\right)=\sup _{x \geq y}\left[\min \left(u_{M 1}(x), u_{M 2}(y)\right)\right],
$$


TABLE 5: Main physical and mechanical properties of stone workpiece.

\begin{tabular}{|c|c|c|c|c|c|c|c|c|c|c|}
\hline Rock properties & G1 & G2 & G3 & G4 & G5 & G6 & G7 & G8 & G9 & G10 \\
\hline $\mathrm{SiO}_{2}(\%)$ & 72.36 & 75.25 & 72.78 & 73.28 & 73.82 & 70.19 & 67.25 & 64.2 & 72.53 & 67.34 \\
\hline Quartz (\%) & 29.2 & 40.3 & 32.15 & 28.7 & 36 & 26.7 & 45.11 & 25.2 & 31.1 & 19.3 \\
\hline Orthoclase (\%) & 20.35 & 41.35 & 56 & 49 & 27.98 & 56.2 & 17.65 & 57.9 & 27.35 & 30.25 \\
\hline Plagioclase (\%) & 42.5 & 13.35 & 10.45 & 13.3 & 20.53 & 13.2 & 25.07 & 8 & 35.26 & 25 \\
\hline Shore hardness (HSD) & 85 & 102 & 98.46 & 111 & 85.14 & 115 & 104 & 90.5 & 101 & 75 \\
\hline Density $\left(\mathrm{g} / \mathrm{cm}^{3}\right)$ & 2.56 & 2.68 & 2.7 & 2.6 & 2.61 & 2.65 & 2.58 & 2.64 & 2.62 & 2.65 \\
\hline Bending strength (MPa) & 8.93 & 15.1 & 20.64 & 14.8 & 20.16 & 17.06 & 17.1 & 12.8 & 12.9 & 7.63 \\
\hline Compression strength (MPa) & 92.3 & 165.9 & 226.3 & 162.5 & 199.48 & 168.29 & 209.9 & 153.8 & 219.3 & 85.69 \\
\hline
\end{tabular}

where sup is the smallest upper bound

$$
\begin{aligned}
& V\left(M_{1} \geq M_{2}\right)=\mu(d) \\
& \quad= \begin{cases}1 & m_{1} \geq m_{2} \\
\frac{l_{2}-u_{1}}{\left(m_{1}-u_{1}\right)-\left(m_{2}-l_{2}\right)} & m_{1} \leq m_{2}, u_{1} \geq l_{2} \\
0 & \text { otherwise. }\end{cases}
\end{aligned}
$$

Definition 3. The possibility of a fuzzy number greater than the other $k$ fuzzy numbers is defined as

$$
\begin{aligned}
V & \left(M \geq M_{1}, M_{2}, \ldots, M_{k}\right) \\
& =V\left[\left(M \geq M_{1}\right),\left(M \geq M_{2}\right), \ldots,\left(M \geq M_{k}\right)\right] \\
& =\min V\left(M \geq M_{i}\right), \quad i=1,2, \ldots, k
\end{aligned}
$$

if $d\left(A_{j}\right)=\min V\left(S_{i} \geq S_{k}\right), k=1,2, \ldots, n, k \neq i$; the final weight vector is described as

$$
w^{\prime}=\left(d^{\prime}\left(A_{1}\right), d^{\prime}\left(A_{2}\right), \ldots, d^{\prime}\left(A_{n}\right)\right)^{T}
$$

Standardized weight vector is obtained through standardized processing as follows:

$$
w=\left(d^{\prime}\left(A_{1}\right), d^{\prime}\left(A_{2}\right), \ldots, d^{\prime}\left(A_{n}\right)\right)^{T} .
$$

\subsection{TOPSIS (Technique for Order Preference by Similarity to} an Ideal Solution). The TOPSIS evaluation method was first proposed by Hwang and Yoon [29] based on the degree of closeness between a limited evaluation object and an ideal goal. TOPSIS evaluation methods are as follows:

(1) Normalizing the evaluation object:

$$
r_{i j}=\frac{w_{i j}}{\sqrt{\sum_{i=1}^{n} w_{i j}^{2}}} .
$$

(2) Constructing a normalized weighting matrix:

$$
v_{i j}=w_{i j} \times r_{i j}
$$

(3) Determining positive and negative ideal solutions:

$$
\begin{gathered}
A^{+}=\left\{v_{1}{ }^{+}, v_{2}{ }^{+}, v_{3}{ }^{+}, \ldots, v_{m}{ }^{+}\right\}^{T}, \\
v_{j}^{+}=\max _{i}\left\{v_{i j}\right\}, j=1,2, \ldots, m, \\
A^{-}=\left\{v_{1}{ }^{-}, v_{2}{ }^{-}, v_{3}{ }^{-}, \ldots, v_{m}{ }^{-}\right\}^{T}, \\
v_{j}^{-}=\min _{i}\left\{v_{i j}\right\}, j=1,2, \ldots, m .
\end{gathered}
$$

(4) Calculating the distance between the evaluated object and the positive and negative ideal:

Distance to ideal solution:

$$
D_{i}^{+}=\sqrt{\sum_{j=1}^{n}\left(v_{j}^{+}-v_{i j}\right)^{2}} .
$$

Distance to negative solution:

$$
D_{i}^{-}=\sqrt{\sum_{j=1}^{n}\left(v_{j}^{-}-v_{i j}\right)^{2}} .
$$

(5) Calculating the closeness of each evaluation index to the ideal solution:

$$
C_{i}=\frac{D_{i}^{-}}{D_{i}^{+}+D_{i}^{-}}, \quad 0 \leq C_{i} \leq 1 .
$$

(6) Determining the ranking of evaluation indexes according to $C_{i}$ values.

\section{Materials and Methods}

Ten granite samples were selected from a stone sawing company and used as the workpiece for the experiments. Table 5 lists the main physical and mechanical properties of the stone workpiece. The rock properties were tested by a construction engineering quality test center in Shandong, China. A uniaxial compressive strength test was carried out using five $50-\mathrm{mm}$ cubic specimens at a $0.6 \sim 0.4 \mathrm{Mpa} / \mathrm{s}$ constant loading rate according to GB/T 9966.1 Chinese 

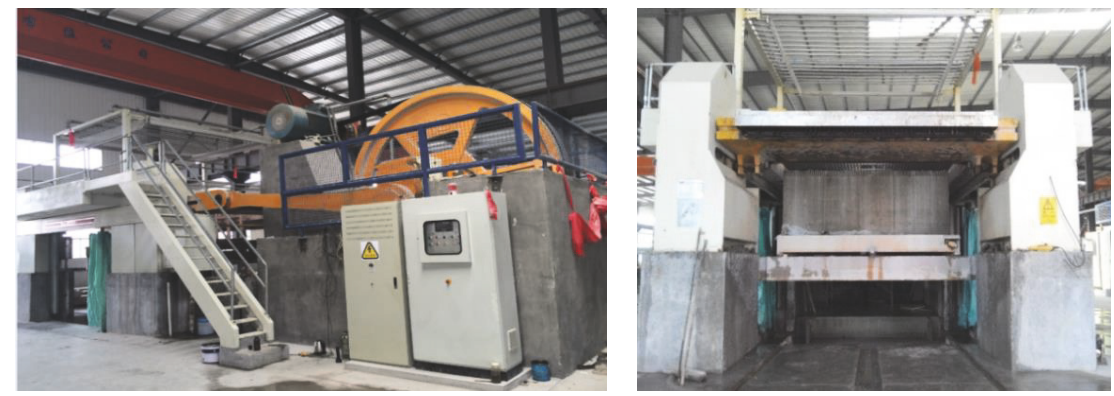

FIGURE 3: Sawing machine.

Standard. Next, the bending strength test was performed using five specimens with dimensions of $20 \mathrm{~mm} \times 40 \mathrm{~mm} \times$ $160 \mathrm{~mm}$ at a $0.2 \mathrm{Mpa} / \mathrm{s}$ loading rate according to GB/T 9966.2 Chinese Standard. The shore hardness test was conducted in accordance with GB/T 9966.5 Chinese Standard using five specimens with dimensions of $20 \mathrm{~mm} \times 100 \mathrm{~mm} \times 100 \mathrm{~mm}$. The distance of the test point from the workpiece edge was greater than $10 \mathrm{~mm}$. A density test was done in accordance with GB/T 9966.3 Chinese Standard using five 50-mm cubic specimens.

A diamond frame saw is typically used to cut large stone blocks $(\sim 2 \mathrm{~m} \times 2 \mathrm{~m} \times 2 \mathrm{~m}$.). Figure 3 shows the sawing machines that can mount 60 120 blades. The stroke of a diamond frame saw is $600 \mathrm{~mm}$. The flywheel speed is $\sim 85 \mathrm{r} / \mathrm{min}$, and the feed rate of the block table is $60 \mathrm{~mm} / \mathrm{h}$. The blade size is $4500 \mathrm{~mm} \times 180 \mathrm{~mm} \times 3.5 \mathrm{~mm}$ and the size of the diamond segments is $20 \mathrm{~mm} \times 10 \mathrm{~mm} \times 4.5 \mathrm{~mm}$. The mesh of the diamond particles is $40 / 50$, and the diamond concentration is 20 .

\section{FAHP-TOPSIS Evaluation of Sawability Using a Diamond Frame Saw to Cut Granite}

4.1. Determining the Standardized Weight. $\mathrm{SiO}_{2}\left(C_{1}\right)$, quartz $\left(C_{2}\right)$, orthoclase $\left(C_{3}\right)$, plagioclase $\left(C_{4}\right)$, shore hardness $\left(C_{5}\right)$, density $\left(C_{6}\right)$, bending strength $\left(C_{7}\right)$, and compression strength $\left(C_{8}\right)$ were chosen as input parameters, and the diamond segment wear was predicted using a diamond frame saw to cut granite.

Twenty decision-makers evaluated the importance of these factors by completing a questionnaire. Seven of the respondents are stone industry professors, graduate students, or other scientific researchers. Seven respondents are granite plate production enterprise managers and workshop workers, and the rest are engineers or people who work in companies that manufacture stone processing equipment. To increase the reliability of the weight factors, each decision-maker scored the parameters according to Table 4 . The pair-wise comparisons of the decision-makers' values are transformed in the fuzzy judgment matrix, as shown in Table 6.

The fuzzy comprehensive value was calculated according to (5), and the initial weights are shown in Table 7. According to (8) and (9), the final weight was determined and is presented in Table 8 . The final weight was standardized, to obtain the normalized weight of the stone parameters.

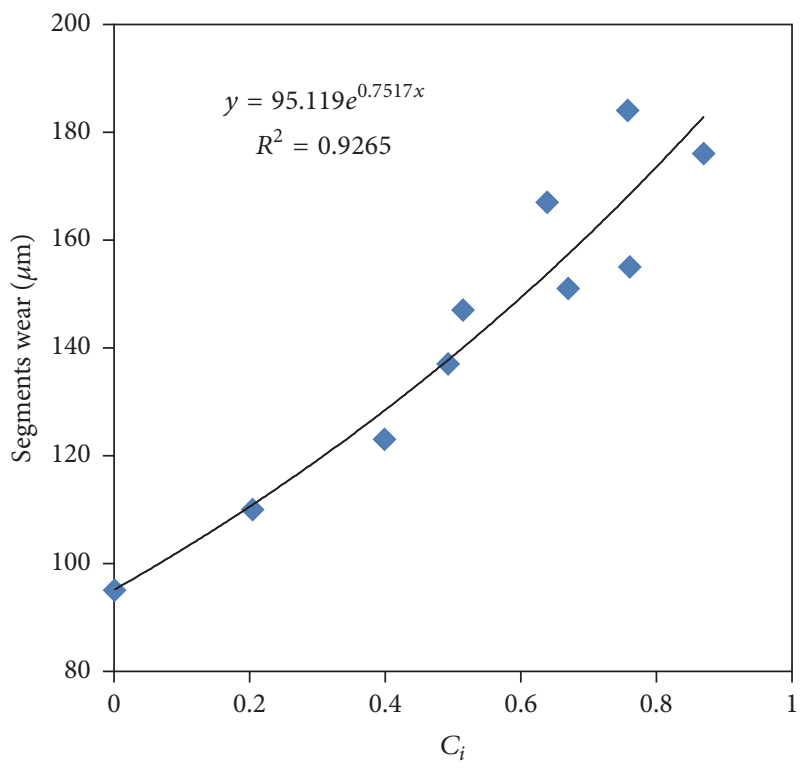

FIGURE 4: Graph of segment wear against $C_{i}$.

4.2. Ranking the Sawability. Because the values of $C_{1}, C_{3}$, $C_{4}$, and $C_{6}$ are zero, stone properties with nonzero values, including quartz $\left(C_{2}\right)$, shore hardness $\left(C_{5}\right)$, bending strength $\left(C_{7}\right)$, and compression strength $\left(C_{8}\right)$, were chosen to rank the sawability, as listed in Table 9.

First, normalization processing of the data was performed by application of (12), as listed in Table 10. Then, a normalized weighting matrix was constructed via (13), as listed in Table 11.

According to (14), the positive and negative ideal solutions are as follows:

$$
\begin{aligned}
& A^{+}=\{0.1386,0.0274,0.0849,0.1703\}, \\
& A^{+}=\{0.0593,0.0178,0.0314,0.0645\} .
\end{aligned}
$$

The evaluation results were determined by application of (15) and (16) and are shown in Table 12.

4.3. Experimental Results. Table 13 lists the experimental results of segment wear as measured by micrometer. A graph of segment wear against $C_{i}$ was constructed, as shown in Figure 4. As segment wear increases, $C_{i}$ increases. The determination coefficient $\left(R^{2}=0.9265\right)$ illustrated that there 


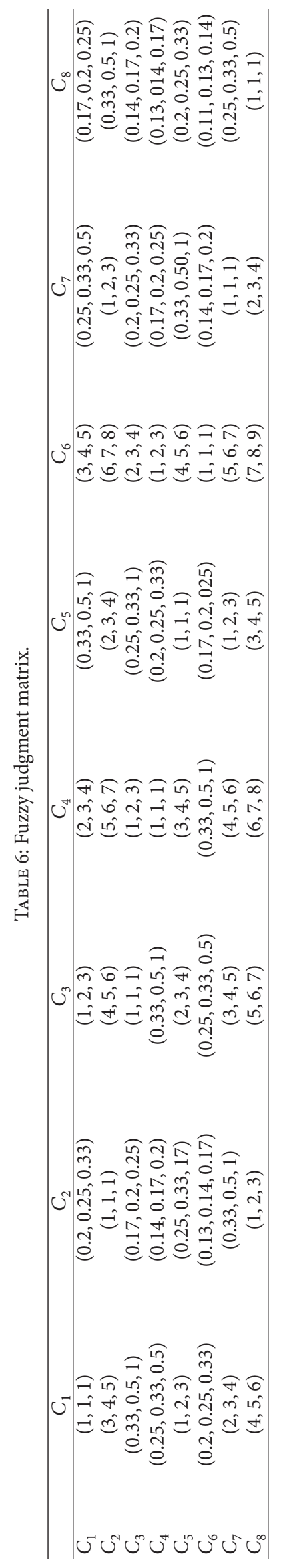


TABLE 7: Initial weight.

\begin{tabular}{lcccc}
\hline & & $l$ & $m$ & $n$ \\
\hline$C_{1}$ & $\mathrm{SiO}_{2}$ & 0.0490 & 0.0878 & 0.1535 \\
$C_{2}$ & Quartz & 0.1377 & 0.2219 & 0.3561 \\
$C_{3}$ & Orthoclase & 0.0314 & 0.0580 & 0.1097 \\
$C_{4}$ & Plagioclase & 0.0198 & 0.0358 & 0.0656 \\
$C_{5}$ & Shore hardness & 0.0726 & 0.1252 & 0.2120 \\
$C_{6}$ & Density & 0.0144 & 0.0212 & 0.0366 \\
$C_{7}$ & Bending strength & 0.1022 & 0.1700 & 0.2798 \\
$C_{8}$ & Compression strength & 0.1787 & 0.2802 & 0.4375 \\
\hline
\end{tabular}

TABLE 8: Final weight and normalized weight.

\begin{tabular}{lcccccccc}
\hline & $C_{1}$ & $C_{2}$ & $C_{3}$ & $C_{4}$ & $C_{5}$ & $C_{6}$ & $C_{7}$ & $C_{8}$ \\
\hline Final weight & 0 & 0.7523 & 0 & 0 & 0.1764 & 0 & 0.4781 \\
Normalized weight & 0 & 0.3126 & 0 & 0 & 0.0733 & 0 & 0.1986 & 0.4155 \\
\hline
\end{tabular}

TABLE 9: Stone parameter data.

\begin{tabular}{lcccc}
\hline Granite & $\begin{array}{c}\text { Quartz }(\%) \\
\left(C_{2}\right)\end{array}$ & $\begin{array}{c}\text { Shore hardness (HSD) } \\
\left(C_{5}\right)\end{array}$ & $\begin{array}{c}\text { Bending strength (MPa) } \\
\left(C_{7}\right)\end{array}$ & $\begin{array}{c}\text { Compression strength (MPa) } \\
\left(C_{8}\right)\end{array}$ \\
\hline G1 & 29.2 & 85 & 8.93 & 92.3 \\
G2 & 40.3 & 102 & 15.1 & 165.9 \\
G3 & 32.15 & 98.46 & 20.64 & 226.3 \\
G4 & 28.7 & 111 & 14.8 & 162.5 \\
G5 & 36 & 85.14 & 20.16 & 199.48 \\
G6 & 26.7 & 115 & 17.06 & 168.29 \\
G7 & 45.11 & 104 & 17.1 & 209.9 \\
G8 & 25.2 & 90.5 & 12.8 & 153.8 \\
G9 & 31.1 & 101 & 12.9 & 219.3 \\
G10 & 19.3 & 75 & 7.63 & 85.69 \\
\hline
\end{tabular}

TABLE 10: Normalized matrix.

\begin{tabular}{|c|c|c|c|}
\hline $\begin{array}{l}\text { Quartz (\%) } \\
\left(C_{2}\right)\end{array}$ & $\begin{array}{l}\text { Shore hardness (HSD) } \\
\qquad\left(C_{5}\right)\end{array}$ & $\begin{array}{l}\text { Bending strength }(\mathrm{MPa}) \\
\qquad\left(C_{7}\right)\end{array}$ & $\begin{array}{l}\text { Compression strength }(\mathrm{MPa}) \\
\qquad\left(C_{8}\right)\end{array}$ \\
\hline 0.2870 & 0.2758 & 0.1850 & 0.1672 \\
\hline 0.3961 & 0.3310 & 0.3127 & 0.3004 \\
\hline 0.3160 & 0.3195 & 0.4275 & 0.4098 \\
\hline 0.2820 & 0.3602 & 0.3065 & 0.2943 \\
\hline 0.3538 & 0.2763 & 0.4175 & 0.3612 \\
\hline 0.2624 & 0.3732 & 0.3533 & 0.3048 \\
\hline 0.4434 & 0.3375 & 0.3542 & 0.3801 \\
\hline 0.2477 & 0.2937 & 0.2651 & 0.2785 \\
\hline 0.3057 & 0.3278 & 0.2672 & 0.3971 \\
\hline 0.1897 & 0.2434 & 0.1580 & 0.1552 \\
\hline
\end{tabular}

was a high statistical correlation between segment wear and the $C_{i}$ value. Thus, the prediction model of sawability is acceptable and reasonable using the FAHP and TOPSIS method. The regression equation of segment wear $y$ and $C_{i}$ value is as follows:

$$
y=95.119 e^{0.7517 x}
$$

\section{Conclusions}

A diamond frame saw is capable of mounting more than 60 blades, each $4500 \mathrm{~mm}$ in length. Twenty-six diamond segments are welded on each blade. Segment wear is directly related to the cutting performance and sawing cost, so an accurate prediction of the segment wear of a diamond frame saw would be beneficial to a stone sawing company. 
TABLE 11: Weighting matrix.

\begin{tabular}{|c|c|c|c|}
\hline $\begin{array}{l}\text { Quartz (\%) } \\
\left(C_{2}\right)\end{array}$ & $\begin{array}{l}\text { Shore hardness (HSD) } \\
\qquad\left(C_{5}\right)\end{array}$ & $\begin{array}{l}\text { Bending strength }(\mathrm{MPa}) \\
\qquad\left(C_{7}\right)\end{array}$ & $\begin{array}{l}\text { Compression strength }(\mathrm{MPa}) \\
\qquad\left(\mathrm{C}_{8}\right)\end{array}$ \\
\hline 0.0897 & 0.0202 & 0.0367 & 0.0695 \\
\hline 0.1238 & 0.0243 & 0.0621 & 0.1248 \\
\hline 0.0988 & 0.0234 & 0.0849 & 0.1703 \\
\hline 0.0882 & 0.0264 & 0.0609 & 0.1223 \\
\hline 0.1106 & 0.0203 & 0.0829 & 0.1501 \\
\hline 0.0820 & 0.0274 & 0.0702 & 0.1266 \\
\hline 0.1386 & 0.0247 & 0.0703 & 0.1579 \\
\hline 0.0774 & 0.0215 & 0.0527 & 0.1157 \\
\hline 0.0955 & 0.0240 & 0.0531 & 0.1650 \\
\hline 0.0593 & 0.0178 & 0.0314 & 0.0645 \\
\hline
\end{tabular}

TABLE 12: Evaluation results.

\begin{tabular}{lccc}
\hline$D^{+}$ & $D^{-}$ & $C_{i}$ & Ranking \\
\hline 0.1222 & 0.0314 & 0.2043 & 9 \\
0.0530 & 0.0938 & 0.6387 & 5 \\
0.0400 & 0.1251 & 0.7577 & 3 \\
0.0737 & 0.0715 & 0.4927 & 7 \\
0.0353 & 0.1124 & 0.7610 & 2 \\
0.0729 & 0.0773 & 0.5145 & 6 \\
0.0193 & 0.1288 & 0.8699 & 1 \\
0.0883 & 0.0585 & 0.3985 & 8 \\
0.0539 & 0.1092 & 0.6696 & 10 \\
0.1430 & 0.0001 & 0.0007 & 10 \\
\hline
\end{tabular}

TABLE 13: Experimental results of segment wear $(\mu \mathrm{m})$.

\begin{tabular}{lllllllllll}
\hline Stones & G1 & G2 & G3 & G4 & G5 & G6 & G7 & G8 & G9 & G10 \\
\hline Wear $(\mu \mathrm{m})$ & 110 & 167 & 184 & 137 & 155 & 147 & 176 & 123 & 151 & 95 \\
\hline
\end{tabular}

The predicted segment wear of granite was studied using FAHP and TOPSIS mathematical methods. FAHP is utilized to determine the weight of factors, and TOPSIS is used to rank the sawability. For validation of the employed ranking method, a sawing experiment was conducted and diamond segment wear was measured and was used as the evaluation criterion. A prediction mathematical model of $C_{i}$ and segment wear was established, and the analysis showed that these two values showed a high statistical correlation. Overall, this ranking method is reasonable and acceptable for evaluating segment wear at a stone sawing company using a diamond frame saw to cut a large granite block $(2 \mathrm{~m} \times$ $2 \mathrm{~m} \times 2 \mathrm{~m}$ ). Segment wear of a diamond frame saw can be determined based on rock properties, such as quartz, shore hardness, bending strength, and compression strength.

\section{Conflicts of Interest}

The authors declare that they have no conflicts of interest.

\section{Acknowledgments}

This research received financial support from the Independent Innovation and Achievement Transformation Special Project of Shandong Province, China (2014CGZH0802). The authors are most grateful to Rizhao Hein Saw Co., Ltd. and Shandong Renown Diamond Tools Co., Ltd. for supporting this work by providing the frame saw, diamond segment, and dimensioned rock samples.

\section{References}

[1] R. Mikaeil, R. Yousefi, and M. Ataei, "Sawability ranking of carbonate rock using fuzzy analytical hierarchy process and TOPSIS approaches," Scientia Iranica, vol. 18, no. 5, pp. 11061115, 2011.

[2] R. Mikaeil, Y. Ozcelik, R. Yousefi, M. Ataei, and S. Mehdi Hosseini, "Ranking the sawability of ornamental stone using Fuzzy Delphi and multi-criteria decision-making techniques," International Journal of Rock Mechanics and Mining Sciences, vol. 58, pp. 118-126, 2013. 
[3] S. Kahraman, H. Altun, B. S. Tezekici, and M. Fener, "Sawability prediction of carbonate rocks from shear strength parameters using artificial neural networks," International Journal of Rock Mechanics and Mining Sciences, vol. 43, no. 1, pp. 157-164, 2006.

[4] S. Kahraman, M. Fener, and O. Gunaydin, "Predicting the sawability of carbonate rocks using multiple curvilinear regression analysis," International Journal of Rock Mechanics and Mining Sciences, vol. 41, no. 7, pp. 1123-1131, 2004.

[5] M. Ataei, R. Mikaiel, F. Sereshki, and N. Ghaysari, "Predicting the production rate of diamond wire saw using statistical analysis," Arabian Journal of Geosciences, vol. 5, no. 6, pp. 12891295, 2012.

[6] D. Tumac, "Artificial neural network application to predict the sawability performance of large diameter circular saws," Measurement, vol. 80, pp. 12-20, 2016.

[7] R. Mikaeil, R. Yousefi, M. Ataei, and R. A. Farani, "Development of a new classification system for assessing of carbonate rock sawability," Archives of Mining Sciences, vol. 56, no. 1, pp. 59-70, 2011.

[8] A. Ersoy and U. Atıc1, "Performance characteristics of circular diamond saws in cutting different types of rocks," Diamond and Related Materials, vol. 13, no. 1, pp. 22-37, 2004.

[9] M. Fener, S. Kahraman, and M. O. Ozder, "Performance prediction of circular diamond saws from mechanical rock properties in cutting carbonate rocks," Rock Mechanics and Rock Engineering, vol. 40, no. 5, pp. 505-517, 2007.

[10] M. Yurdakul and H. Akdaş, "Prediction of specific cutting energy for large diameter circular saws during natural stone cutting," International Journal of Rock Mechanics and Mining Sciences, vol. 53, pp. 38-44, 2012.

[11] B. Tutmez, S. Kahraman, and O. Gunaydin, "Multifactorial fuzzy approach to the sawability classification of building stones," Construction and Building Materials, vol. 21, no. 8, pp. 1672-1679, 2007.

[12] N. S. Delgado, A. Rodríguez-Rey, L. M. Suárez del Río, I. Díez Sarriá, L. Calleja, and V. G. Ruiz de Argandoña, "The influence of rock microhardness on the sawability of Pink Porrino granite (Spain)," International Journal of Rock Mechanics and Mining Sciences, vol. 42, no. 1, pp. 161-166, 2005.

[13] X. P. Xu and Y. F. Zhang, "Neural network prediction of segment wear in stone sawing," Materials Science Forum, vol. 471, pp. 485-489, 2004.

[14] X. Wei, C. Y. Wang, and Z. H. Zhou, "Study on the fuzzy ranking of granite sawability," Journal of Materials Processing Technology, vol. 139, no. 1-3, pp. 277-280, 2003.

[15] A. S. Eyuboglu, Y. Ozcelik, S. Kulaksiz, and I. C. Engin, "Statistical and microscopic investigation of disc segment wear related to sawing Ankara andesites," International Journal of Rock Mechanics and Mining Sciences, vol. 40, no. 3, pp. 405-414, 2003.

[16] A. Ersoy, S. Buyuksagic, and U. Atici, "Wear characteristics of circular diamond saws in the cutting of different hard abrasive rocks," Wear, vol. 258, no. 9, pp. 1422-1436, 2005.

[17] Y. Özçelik, "The effect of marble textural characteristics on the sawing efficiency of diamond segmented frame saws," Industrial Diamond Review, vol. 67, no. 2, pp. 65-70, 2007.

[18] I. S. Buyuksagis, "Effect of cutting mode on the sawability of granites using segmented circular diamond sawblade," Journal of Materials Processing Technology, vol. 183, no. 2-3, pp. 399-406, 2007.

[19] I. S. Buyuksagis and R. M. Goktan, "Investigation of marble machining performance using an instrumented block-cutter,"
Journal of Materials Processing Technology, vol. 169, no. 2, pp. 258-262, 2005.

[20] R. Mikaeil, M. Z. Naghadehi, M. Ataei, and R. Khalokakaie, "A decision support system using fuzzy analytical hierarchy process (FAHP) and topsis approaches for selection of the optimum underground mining method," Archives of Mining Sciences, vol. 54, no. 2, pp. 349-368, 2009.

[21] L. A. Zadeh, "Fuzzy sets," Information and Control, vol. 8, no. 3, pp. 338-353, 1965

[22] P. J. M. van Laarhoven and W. Pedrycz, "A fuzzy extension of Saaty's priority theory," Fuzzy Sets and Systems, vol. 11, no. 3, pp. 229-241, 1983.

[23] D. Chang, "Applications of the extent analysis method on fuzzy AHP," European Journal of Operational Research, vol. 95, no. 3, pp. 649-655, 1996.

[24] M. Z. Naghadehi, R. Mikaeil, and M. Ataei, "The application of fuzzy analytic hierarchy process (FAHP) approach to selection of optimum underground mining method for Jajarm Bauxite Mine, Iran," Expert Systems with Applications, vol. 36, no. 4, pp. 8218-8226, 2009.

[25] A. H. Hu, C.-W. Hsu, T.-C. Kuo, and W.-C. Wu, "Risk evaluation of green components to hazardous substance using FMEA and FAHP," Expert Systems with Applications, vol. 36, no. 3, pp. 71427147, 2009.

[26] T. L. Saaty, The Analytic Hierarchy Process, McGraw-Hill, New York, NY, USA, 1980.

[27] O. Cakir and M. S. Canbolat, "A web-based decision support system for multi-criteria inventory classification using fuzzy AHP methodology," Expert Systems with Applications, vol. 35, no. 3, pp. 1367-1378, 2008.

[28] D. Y. Chang, "Extent analysis and synthetic decision," Optimization techniques and applications, vol. 1, no. 1, pp. 352-355, 1992.

[29] C. L. Hwang and K. Yoon, "Methods for multiple attribute decision making," in Multiple attribute decision making, pp. 58-191, Springer Berlin Heidelberg, Heidelberg, Germany, 1981. 


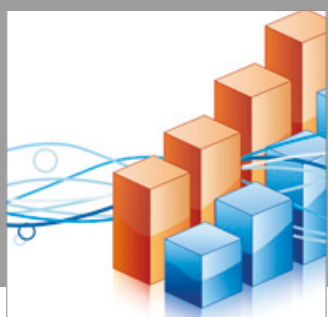

Advances in

Operations Research

vatersals

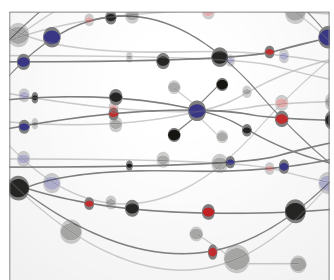

\section{The Scientific} World Journal
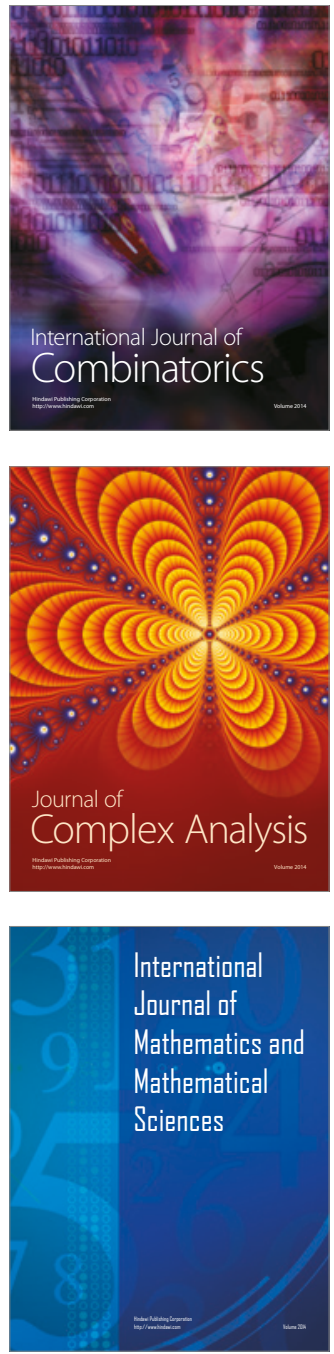
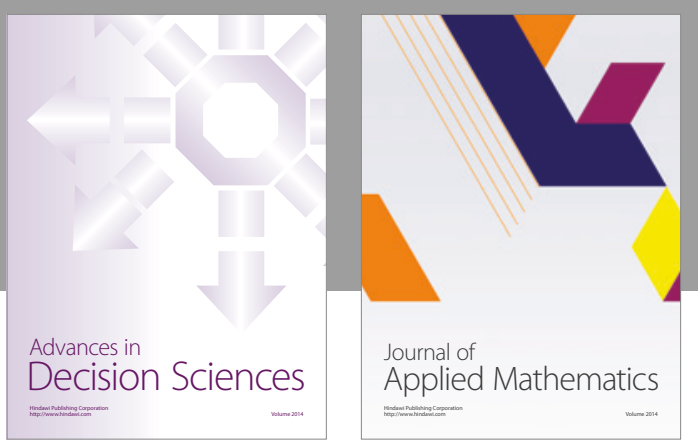

Algebra

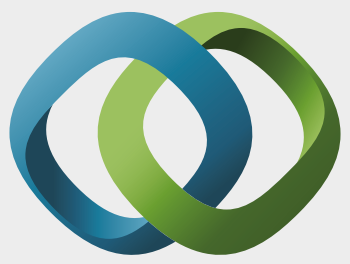

\section{Hindawi}

Submit your manuscripts at

https://www.hindawi.com
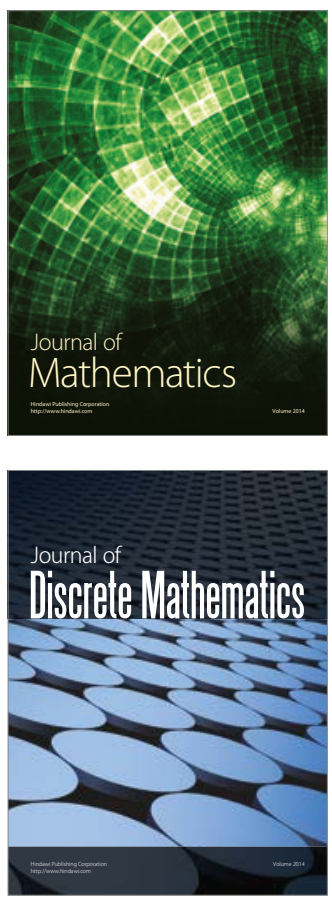

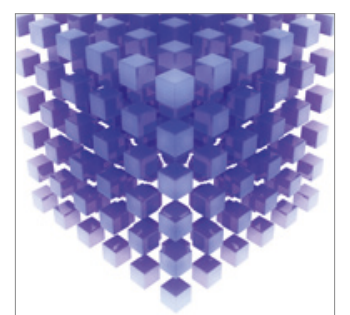

Mathematical Problems in Engineering
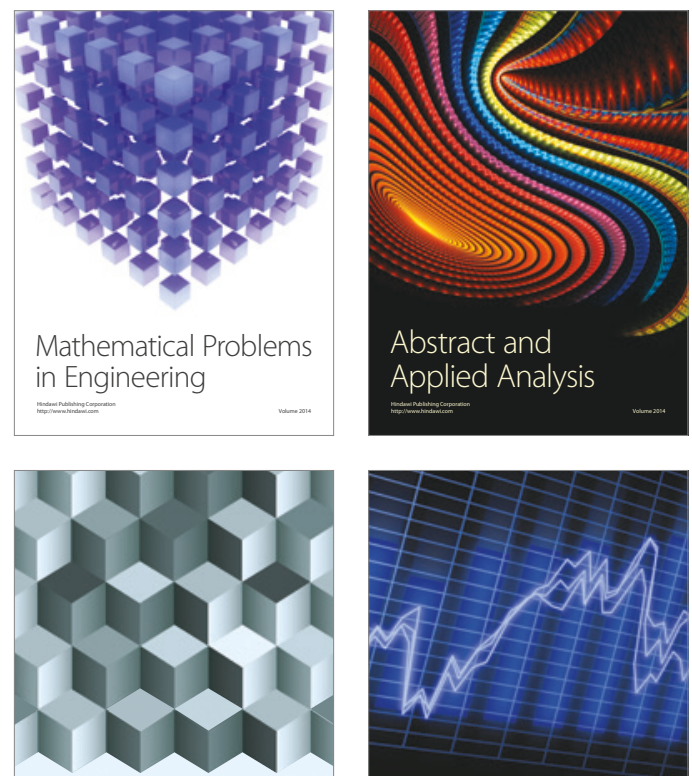

Journal of

Function Spaces

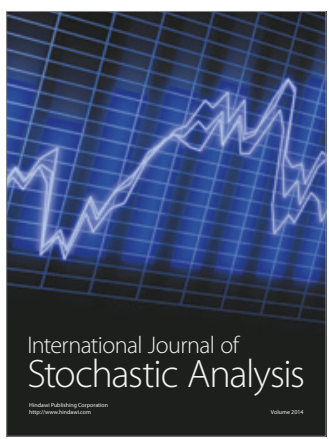

Probability and Statistics
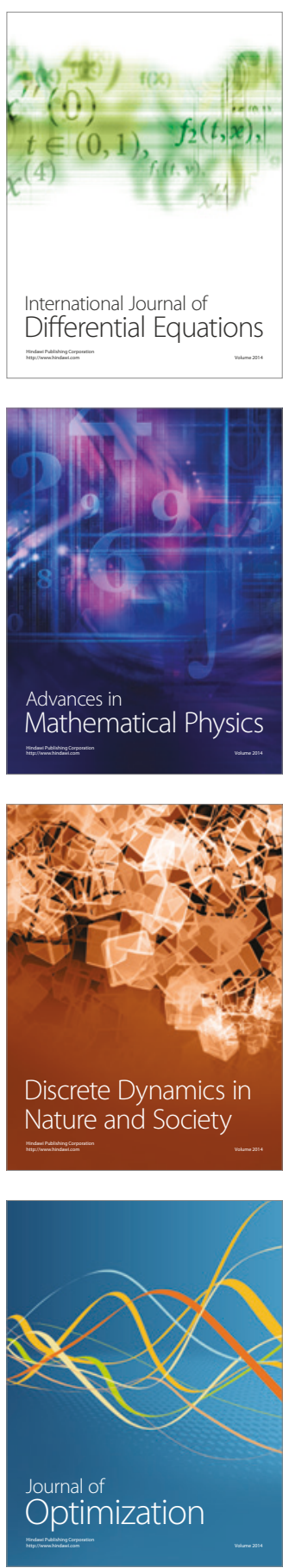